\title{
Por qué en defensa de la sociología: una extensión del manifiesto sociológico para tiempos de oscuridad
}

\author{
Adrián Galindo Castro ${ }^{1}$
}

\author{
Fecha de recepción: 20 de agosto de 2019 \\ Fecha de aprobación: 17 de octubre de 2019 \\ Fecha de publicación: 31 de diciembre de 2019
}

\begin{abstract}
Resumen
En diversas épocas y lugares, se ha puesto en duda el valor que tiene la sociología como ciencia y como profesión. El más reciente episodio de esta trama se presentó en Brasil, cuando el presidente en funciones, Jair Bolsonaro, anunció el retiro del financiamiento a los programas de licenciatura en sociología de las universidades federales. En el presente artículo, se analizan los cambios producidos en la forma de hacer sociología y el papel que juega esta ciencia social en las sociedades en las que está inserta. De manera particular, se examinan los giros teóricos y metodológicos que ha tenido la sociología en América Latina a partir de grandes procesos históricos como la industrialización, la crisis de la deuda externa y el neoliberalismo. Se vinculan estas etapas históricas con enfoques teóricos como la teoría de la modernización, la dependencia y la decolonialidad. Finalmente, se sostiene que vivimos un periodo de prueba para demostrar la importancia de la sociología.
\end{abstract}

Palabras clave: América Latina, defensa, sociología.

\section{Why defend sociology: an extension of the sociological manifesto in times of darkness}

\begin{abstract}
The value of sociology as a science and as a profession has been questioned in different places and eras. The most recent episode of this plot was seen in Brazil, when the president in office, Jair Bolsonaro, announced the withdrawal of funding for sociology degree programs at federal universities. This article analyzes the changes produced in the way of doing sociology and the role that this social science plays in the societies where it is found. In particular, the theoretical and methodological changes that sociology has undergone in Latin America are examined based on great historical processes
\end{abstract}

Doctor en sociología por la Universidad Autónoma Metropolitana, México. Universidad Autónoma del Estado de Hidalgo, Pachuca de Soto, Hidalgo, México. Contacto: galindo_adrian@hotmail.com 
Por qué en defensa de la sociología: una extensión del manifiesto sociológico para tiempos de oscuridad -

Galindo

such as industrialization, the external debt crisis and neoliberalism. These historical stages are linked to theoretical approaches, such as the theory of modernization, dependency and decoloniality. Finally, it is argued that we live in a trial period for demonstrating the importance of sociology.

Key words: Latin-America, defense, sociology.

\title{
Por que em defesa da sociologia: uma extensão do manifesto sociológico para tempos de obscuridade
}

\begin{abstract}
Resumo
Em diversas épocas e lugares, o valor da sociologia como ciência e profissão tem sido colocado em dúvida. O mais recente episódio desta trama se apresentou no Brasil, quando o presidente em exercício, Jair Bolsonaro, anunciou a retirada do financiamento dos programas do curso de sociologia das universidades federais. Neste artigo, são analisadas as mudanças produzidas na forma de se praticar a sociologia e o papel desempenhado por esta ciência social nas sociedades onde está inserida. De maneira particular, são examinados as transformações teóricas e metodológicas da sociologia na América Latina a partir de grandes processos históricos como a industrialização, a crise da dívida externa e o neoliberalismo. Vinculamse estas etapas históricas com perspectivas teóricas como a teoria da modernização, a dependência e a decolonialidade. Finalmente, defende-se a ideia de que vivemos um período de teste para demonstrar a importância da sociologia.
\end{abstract}

Palavras-chave: América Latina, defesa, sociologia.

\section{Introducción: La existencia como sospecha}

La sociología es una ciencia incómoda. Desde sus inicios, la sociología fue cuestionada por ser una ciencia carente de materia de estudio o, por el contrario, por sus pretensiones de monopolizar el estudio del universo social ${ }^{2}$. De igual modo, a la sociología frecuentemente se le ha imputado la falta de un cuerpo unificado y sistemático de conceptos y, en el mismo sentido, adolecer de una conexión entre las múltiples teorías o ten-

\footnotetext{
2 Norman Birdnbaum apunta que la sociología fue desde un principio una disciplina extremadamente sintética. Puso al día la filosofía política intentando objetivar algunos dilemas morales. De la economía política, la sociología extrajo la idea de la innovación y la magnitud del mercado. La historia le dio a la sociología un sentido de cambio y relatividad. La estadística social le proporcionó los elementos de una descripción concreta de la nueva sociedad (Birnbaum, 1982).
} 
dencias teóricas y la investigación social que realiza (Bourdieu, 2008); a ello se añade las dudas sobre la trascendencia o la utilidad social de los resultados obtenidos (Requena Santos, 2014). A pesar de las dificultades, al alcanzar una irrefutable institucionalización como disciplina académica, la sociología gozó de cierta estabilidad en el ámbito de la educación superior, como carrera universitaria y como conocimiento válido, ambos productos útiles para las instituciones educativas, culturales, políticas y económicas.

No obstante, en diversos tiempos y en varias latitudes la existencia de la sociología como ciencia y como profesión ha sido puesta en duda y, en casos extremos, prohibida como un conocimiento y práctica social legítimos de las sociedades modernas (Portes, 2004; Touraine, 1978). El último episodio de esta confabulación lo constituye el anuncio, a principios de 2019, del presidente brasileño Jair Bolsonaro de suspender los recursos económicos destinados a solventar el sostenimiento de las carreras universitarias de sociología y filosofía en todo Brasil, esgrimiendo argumentos ambiguos e insostenibles.

Técnicamente, el ex capitán Bolsonaro ha recurrido al mecanismo del financiamiento público para asfixiar a las ciencias sociales y a las humanidades, identificando a la sociología y a la filosofía como los abanderados de esas disciplinas críticas a las que trata de silenciar. Por su lado, las asociaciones de sociólogos han respondido lanzando a la red comunicados (Consejo Latinoamericano de Ciencias Sociales (CLACSO), 2019), donde se solicita la adhesión de la comunidad académica del continente para frenar esta embestida del gobierno conservador que accedió al gobierno después del interinato golpista que defenestró al gobierno progresista de Dilma Rousseff.El desenlace de esta historia probablemente sea decidido por las fuerzas sociales e institucionales que están enfrentadas, y de los apoyos y recursos de los que se valgan las facultades de sociología de Brasil para sobrevivir al embate del ultraconservador Bolsonaro y sus secuaces. Resulta trágico que sea en uno de los países con mayor tradición socioló- 
gica en el ámbito latinoamericano ${ }^{3}$ donde el ascenso al poder de un mandatario que elogia el golpe miliar de 1964, elevándolo a la categoría de acto heroico, sea quien haga valer la razón de la fuerza frente a la fuerza de la razón. Los principios que supuestamente guían la constitucionalidad democrática del actual Brasil y que se expresan desde el lema de la bandera del país amazónico "Amor, orden y progreso" inspirados en las ideas de Augusto Comte, han resultado poco efectivos para enfrentar un proyecto de desmantelamiento de tres periodos gubernamentales de gobiernos progresistas y más de cincuenta años de vida académica institucional de la sociología en Brasil.

Cabe preguntarse por qué fue la sociología, y no otra u otras ciencias sociales que comparten con la primera un aparato crítico, y en no pocas ocasiones contestatario, la que fue blanco de los ataques del presidente y su ministro de educación. ¿Acaso solo la sociología constituye un desafío al pensamiento reaccionario y, por el contrario, otras ramas del conocimiento científico-social o artístico, como la pedagogía o la psicología, la literatura o el cine no provocan -en quienes reciben cursos o acceden a lecturas y proyecciones - la necesidad de cambios en las variadas formas de convivencia humana y en las formas de distribución de la riqueza o la manera de conducir el orden político? Pero, como ya se apuntó, a diferencia de otras ciencias, la sociología ha sido cuestionada habitualmente y las agresiones de Bolsonaro solo constituyen un incidente más en el largo camino de la sociología por consolidar su posición en los espacios educativo, científico y profesional.

\footnotetext{
$\mathrm{Al}$ respecto, Hélgido Trindade señala que, además de las instituciones de Sao Paulo, las ciencias sociales tuvieron un importante desarrollo entre 1940 y 1960 en Río de Janeiro, Bahía, Pernambuco, Minas Gerais, Pará y Río Grande do Sul. Con la reforma universitaria de 1968 se dio una fuerte expansión de las ciencias sociales producto de los posgrados, de las becas de estudio en el interior del país y en el extranjero, y del financiamiento de la investigación (Trindade, 2007, p. 10).
} 
Precisamente, por esta situación, en diversos tiempos y lugares, los sociólogos han construido una serie de argumentaciones que, más que fundamentar el quehacer de ellos mismos desde un punto de vista epistemológico o metodológico — de este último tipo existen abundantes materiales producidos para consumo de los propios especialistas (Giddens, 1997; Habermas, 2011; Lahire, 2006; Ogien, 2008; Passeron, 2011) —, constituyen en su conjunto un manifiesto de la sociología encaminado a hacer valer su existencia institucional y su utilidad pública y, en este sentido, revertir aquellas críticas que apuntan a su enclaustramiento o a su extinción. Esos documentos, a manera de proclama reivindicativa, constituyen la mejor "defensa de la sociología", título este de sendos libros que alertan sobre la amenaza que se cierne en contra de la disciplina sociológica (Giddens, 2000; Lahire, 2016) frente a quienes vituperan este tipo de conocimiento así como a los productores del mismo, con argumentos tan falaces como los de Bolsonaro.

\section{La falacia de Bolsonaro}

Lo novedoso del desafortunado episodio protagonizado por Jair Bolsonaro en Brasil ha sido, hasta el momento, el no haber acudido al ejército o la policía para buscar clausurar las facultades de sociología y filosofía. En cambio, ha apelado al expediente de la funcionalidad y eficientismo del gasto público. Esta misma estrategia ha posibilitado a los afectados poder recurrir a la movilización y la presión nacional e internacional para frenar, no solo la acometida a las dos disciplinas mencionadas (Armenakas, 2019) sino a la drástica reducción del financiamiento gubernamental a las universidades públicas y al desarrollo de la investigación científica, en general, que se produce en el país sudamericano. Para comprender la tozudez del gobernante carioca y su empeño por desmantelar los logros alcanzados en el campo de las ciencias sociales en la nación de la verde amarela, es necesario retomar cuáles son sus referentes ideológicos y cómo ha presentado Bolsonaro y sus ministros de educación la justificación de las medidas por tomar. 
La mayor inspiración de lo que equivaldría a un ascendente intelectual de Jair Bolsonaro proviene de las ideas de un personaje autodidacta radicado en los Estados Unidos, el cual presume enseñar filosofía por internet. Olavo de Carvalho abiertamente se pronuncia en contra del globalismo, el marxismo cultural y el feminismo, y mantiene una notable influencia en el mandatario y en los dos funcionarios, Ricardo Velez (quien no duró ni tres meses en el cargo) y Avraham Weintraub, que han ocupado la titularidad del ministerio de educación en el gabinete de Bolsonaro (Galarraga, 2019a). Las afinidades del pensamiento de Carvalho con los temas de campaña de Jair Bolsonaro se corresponden plenamente (Galarraga, 2019a). A decir de la reportera, Bolsonaro jamás ha ocultado que considera las universidades un nido de rojos peligrosos y, la calidad de la educación, nefasta. Durante la campaña electoral propuso implantar "la educación a distancia porque así ayudamos a combatir el marxismo"; erradicar lo que denomina "el marxismo cultural" y "la ideología de género" de las aulas es una de sus obsesiones (Galarraga, 2019b). Las amenazas y agresiones no quedaron en el fragor de la campaña. Como respuesta a las masivas movilizaciones del 15 mayo en Sao Paulo, Río de Janeiro, Brasilia y Belo Horizonte, Bolsonaro, quien en esos momentos realizaba una visita a los Estados Unidos, declaró desde Dallas que los estudiantes eran "tontos útiles, unos imbéciles, que están siendo utilizados por una minoría que compone el núcleo de las universidades federales de Brasil" (Jacá \& Galarraga, 2019).

El descontento se generalizó a finales de abril de 2019, mes en que asumió el cargo Avraham Weintraub, un economista de 47 años, graduado en administración de empresas y quien, en los primeros días de su gestión al frente de la cartera de educación, anunció originalmente un recorte de $30 \%$ del presupuesto a tres universidades federales y la eliminación de 3,000 becas para cumplir con los objetivos del déficit. El ministro refirió en varias ocasiones que se ha invertido mucho en educación sin que se hayan visto resultados válidos, afirmando, implícitamente, que se 
ha malgastado el dinero destinado a la educación superior. Al poco tiempo de amenazar con las primeras sanciones, el propio Weintraub amplió las medidas al dar aviso en el sentido de que la reducción se extendía a toda a la red de universidades federales (69 en total). Cabe destacar que todas ellas ofrecen educación de pregrado y posgrado totalmente sin costo y diversos servicios para la comunidad, como cursos de extensión, oficinas de asistencia legal y hospitales (Global Voices, 2019).Al notificar que cortaría las subvenciones a las primeras universidades, Weintraub justificó su decisión diciendo que había "bedlam" (desorden y caos) en estos recintos. Cuando los reporteros le pidieron que diera ejemplos de ese "caos", mencionó la presencia de movimientos sociales en universidades y "fiestas con personas desnudas" (Global Voices, 2019). Ante las inconformidades suscitadas, el ministro de educación rehizo sus declaraciones, diciendo que no se trataba de "recortes" sino que de una "contingencia de gastos" al echar mano a cien chocolatinas para explicar, de manera didáctica, los recortes en una retransmisión de Facebook junto a Bolsonaro (Galarraga, 2019b).Por su lado, Jair Bolsonaro (declarado admirador de Donald Trump), emulando al presidente estadounidense en hacer política por medio de comunicados a través de las redes sociales, notificó por Twitter la intención de su gabinete de detener la inversión monetaria en carreras que no proporcionen empleo y renta para las arcas del país de forma inmediata. Bolsonaro señaló que la medida tenía como objetivo resguardar la inversión de los ciudadanos brasileños y los bienes de la sociedad (Noticias de América Latina (Nodal), 2019). El mandatario brasileño añadió que

la función del gobierno es respetar el dinero del contribuyente, enseñando a los jóvenes la lectura, la escritura y hacer cuentas, y después un oficio que genere renta para la persona y bienestar para la familia, que mejore a la sociedad de su entorno (Nodal, 2019).Posteriormente, Weintraub pormenorizó el plan del gobierno para la educación superior. El objetivo es enfocarse en áreas que 
generen retorno inmediato al contribuyente, como veterinaria, ingeniería y medicina. El ministro brasileño desestimó la importancia del estudio de carreras humanistas a las que catalogó de poco rentables. "Necesitamos elegir mejor nuestras prioridades porque nuestros recursos son escasos. Me gusta la filosofía, pero imaginen una familia de agricultores cuyo hijo entró a la facultad y cuatro años después vuelve con un título de antropólogo". (Nodal, 2019).

Los argumentos instigadores y falaces del gobierno de Bolsonaro no son simples patrañas destinadas a servir de distractor para evadir problemas mayores que enfrenta su gobierno. El impacto que tienen estas declaraciones en la opinión pública desacredita mucho el papel de las ciencias sociales en amplias parcelas de la sociedad civil brasileña. El triunfo electoral del mandatario brasileño refleja el clima de animadversión que prevalece en las capas medias y altas del país sudamericano no solo hacia los gobiernos progresistas, acaso más hacia los movimientos intelectuales como el feminismo o el multiculturalismo que estuvieron a la vanguardia durante ese mismo periodo gracias a la apertura y financiamiento que se brindó a las universidades públicas. Como percibimos, por las propias palabras de Bolsonaro al indicar que trata de "deconstruir" lo que se ha hecho en Brasil desde el retorno a la democracia, el retiro del financiamiento a los programas universitarios de sociología y filosofía, más que obedecer a razones económicas, se trata de un revanchismo ideológico. Quienes salen peor paradas son dos disciplinas caracterizadas por su pensamiento crítico y su poca aplicabilidad técnica. En el caso de la sociología, esta solo se reduce, según las autoridades brasileñas, a preparar profesionales desocupados, sin ninguna contribución social tangible.

Independientemente de estar enfrentando un gobierno retrógrado que busca silenciar las voces críticas, la sociología en Brasil ,tal como ha sucedido en otros países, ha sido puesta en entredicho por la sospecha acerca de su utilidad social. El cuestiona- 
miento actual no gira en torno a la influencia que pudiera ejercer la sociología en la formación de la conciencia social, sino en la posibilidad de esta ciencia por formar profesionistas con un campo de actividad claro para el común de la gente. En esta dirección, se han elaborado diversas respuestas por parte de miembros de la colectividad académica a lo que parece un desconocimiento o un desinterés externo para con la sociología. Es en este sentido que el esfuerzo de algunos sociólogos por dar mayor certeza a la actividad sociológica (más allá de los espacios académicos) se puede resumir en una expresión que manifiesta el tono reivindicativo que justifica la propia de existencia de nuestra disciplina: ¿para qué sirve la sociología?

\section{La radicalidad atribuida a la sociología}

Vivimos tiempos donde el predominio de los grandes poderes económicos, políticos e ideológicos, que dirigen las finanzas internacionales, conducen las políticas de los gobiernos, controlan los medios de comunicación masiva, de igual forma están definiendo progresivamente el perfil que deben tomar los centros de producción científica, incluyendo las instituciones de enseñanza superior públicas. Cada vez es mayor la exigencia para los programas educativos de rendir cuentas, comprobar su viabilidad, su rentabilidad y su pertinencia en cuanto a la oferta para satisfacer los requerimientos de los sectores productivos y los mercados de trabajo profesionales. Se ponen en duda profesiones y actividades que no trabajen bajo la tónica del productivismo, de la satisfacción de los usuarios y de los estándares de la excelencia y la calidad. En este escenario, los sociólogos en muchas partes del orbe han tenido que elaborar una serie de contra argumentaciones ante las críticas burocrático-gubernamentales o mediático-conservadoras empeñadas en desacreditar la disciplina sociológica. Con anterioridad al apremio del "único capitalismo exportable", de acuerdo a la expresión de Boaventura de Sousa (Velázquez, 2019), el espacio de independencia logrado para las 
profesiones universitarias se sustentaba en el principio de autonomía de las ciencias y humanidades. El mismo concepto de "facultad", bajo el que se agrupan disciplinas afines, les otorgaba, hasta hace poco, la capacidad para gobernarse a sí mismas en lo referente a sus planes y programas. El trabajo académico establece sus propias obligaciones en cuanto a preparación del personal que imparte cátedra, acreditación de cursos, generación de materiales didácticos, productos de investigación, entre las funciones más importantes. En eso, la sociología comparte con todos los programas académicos que se imparten en las universidades las mismas reglas y las mismas responsabilidades. Entonces, ¿por qué es a la sociología a la que se le cuestiona?

Una pista para encontrar la animadversión a la sociología por agentes ajenos al campo científico es la asociación de la sociología con un retrato predominantemente radical de su práctica pública y de su producción académica. La imagen negativa de la sociología, como una sociología exclusivamente crítica (algunos, como el mandatario brasileño, sólo le atribuyen una carga corrosiva), adquiere tintes mucho más doctrinarios que imparciales. Ninguna de las diatribas desatadas contra la sociología en el pasado y en el presente ha sido sustentada en una valoración serena de la contribución que esta ciencia ha aportado desde su instauración como ciencia social y como programa académico. Al contrario de lo que musitan sus críticos, la sociología es uno de los productos más logrados del espíritu de la ilustración. El esfuerzo de la sociología por comprender los fenómenos morales a través de los lentes de la razón ha posibilitado desmantelar los discursos obcecados que nutren a los totalitarismos y autoritarismos de todo tipo. A partir de sus indagaciones, la sociología pone en evidencia los intereses que guían a grupos que, desde posiciones de poder, envían mensajes irracionales de odio. La sociología, al rebatir - a partir del estudio riguroso de los factores sociales que las determinan - las prácticas sociales que producen, reproducen y justifican el clasismo, el racismo y todas las demás formas de discriminación, contribuye a erradicarlas. Sin duda, a pesar de 
no contar con un inventario puntual de todas sus aportaciones, la sociología ha contribuido a construir un mundo mejor.

Sin embargo, y debido a sobrepasar los límites de una ciencia convencional, en ciertos periodos de la sociología han existido lapsos donde el revuelo público y el debate interno se anteponen al trabajo científico o al análisis mesurado. Agudo testigo de los cambios sociales que se presentan, el trabajo sociológico se ha visto arrastrado también por la intensidad de las luchas simbólicas que redefinen el orden social. Una gran proporción de sociólogos adquieren consciencia de las desigualdades e injusticias sociales; los jóvenes que descubren su vocación profesional son atraídos por la sociología, precisamente, por ese idealismo de querer trasformar el estado de cosas existente. Debido al interés por estudiar los factores que inciden en el sufrimiento humano, esta disciplina, invariablemente, es una ciencia comprometida, con independencia de la corriente teórica, matriz metodológica o procedimientos técnicos utilizados para producir conocimiento.

La tensión entre neutralidad valorativa y una adhesión ideológica seductora (en las décadas de los 60 y 70 del siglo XX, época de fuertes compromisos ético-políticos, se manifestaba como la diferencia entre sociología marxista y sociologías burguesas) nubló por momentos la lucidez que debe prevalecer en el debate epistemológico y programático para el avance del conocimiento científico y el papel institucional que juega esta ciencia en el marco de la educación superior. En todo caso, en muy pocas ocasiones se hizo explícito el lugar que debía ocupar el compromiso moral del sociólogo. Al respecto, David Colefax (Kon, 1982, p. 38), uno de los líderes estadounidenses de la sociología radical, hizo la distinción entre: radicalismo participativo, que forma parte de la responsabilidad social del científico que lucha conscientemente por contribuir mediante sus estudios a la causa de la liberación de los pueblos oprimidos; el radicalismo cultural, que parte de la identificación de sociólogo con la contracultura y formas experimentales de vida comunitaria; el radicalismo temático, que no requiere la adopción de una postura política clara 
y se reduce al estudio, con métodos tradicionales, de problemas como la pobreza, el racismo, el imperialismo y los movimientos revolucionarios; y el radicalismo filosófico, que centra su atención en la crítica de los principios teóricos y metodológicos de la sociología institucionalizada (Kon, 1982, p. 39). El período de la sociología radical fue, al igual que el lapso en el que predominó el enfoque de la dependencia en América Latina, un intervalo de intensa proyección de la disciplina en el ámbito académico y de significativa influencia en la opinión pública. Junto a la notoriedad que adquirió en el periodo inmediato de la posguerra, el análisis estructural funcionalista, encabezado por Talcott Parsons, constituyeron, en conjunto, los años dorados de la sociología. (Picó, 2003).

Durante el siglo XX, a los convulsionados años 60 le sucedieron unos recesivos años 70; el clima cultural cargado de rebeldía juvenil fue reemplazado en el gran público por una situación de desencanto, que fue el origen del giro conservador que inauguraron Ronald Reagan y Margaret Thatcher. En los países industrializados siguieron existiendo espacios de insurrección como el pacifismo, el ambientalismo, el feminismo, los mismos que constituyeron la plataforma para la formación de organizaciones establecidas de manera permanente.

No obstante, este tipo de activismo fue desligándose cada vez más del quehacer universitario. La influencia de la sociología en este tipo de movimientos fue mínima; la disciplina sociológica no proveyó de ningún marco teórico o esquema programático acerca de qué tipo de sociedad era deseable y posible reconstituir. Muerta la utopía, el improcedente discurso revolucionario fue aislándose de las nuevas demandas sociales, lo mismo que la afluencia de estudiantes a las facultades y escuelas de sociología. Las críticas llevadas a cabo por la sociología radical en contra del estructural funcionalismo parsoniano y otras maneras de trabajo sociológico fundamentado en la investigación social (Gouldner, 2000; Wright Mills, 2004) desalentó por algún tiempo el retorno a una profesionalización de la disciplina, debido a que esta moda- 
lidad se veía como una forma de ingeniería social. El predominio del marxismo persistió por algún tiempo pero esta corriente entró a su vez en una fuerte crisis con el derrumbe del socialismo. Las temáticas dentro del debate sociológico pasaron de la crisis del capitalismo (Habermas, 1999), a la crisis del marxismo (Anderson, 1979), a la crisis de la sociología (Ferrarotti, 1982). Viéndolo en retrospectiva, el afán revolucionario hizo perder el piso a los seguidores de este tipo de sociología. El agotamiento del discurso radical pronto se vio reflejado en una recomposición de las propuestas sociológicas, mucho menos proclives a caer nuevamente en el profetismo (Bourdieu, Chamboderon \& Passeron, 1981) y más a reposicionarse dentro del campo de la ciencia social por medio de la fundamentación epistemológica (Giddens, 1997). La necesidad de someter a una constante revisión las antiguas y nuevas ideas hizo necesaria una recuperación del pensamiento sociológico en su conjunto y abandonar la pretensión de poseer el monopolio de la verdad sociológica, descalificando a las demás escuelas o corrientes como meras ideologías.

\section{Recuperar la tradición y redescubrir la utilidad}

La sociología, como disciplina científica, no apareció en el panorama académico e intelectual de forma súbita o por una moda de época. Esta ciencia es producto del dilatado paso que ha acompañado a las modernas sociedades europeo-occidental y estadounidense, primero, y de los proyectos de modernización de prácticamente todas las naciones pos-tradicionales, después, en la búsqueda de respuestas a su existencia colectiva ${ }^{4}$. La sociología es resultado de un extenso proceso de racionalización constituido por dos elementos esenciales: por un lado, diversos

\footnotetext{
$4 \quad$ El momento de consolidación institucional aconteció en la posguerra cuando se formó la Asociación Internacional de Sociología (ISA por sus siglas en inglés). Esta agrupación forma parte del Consejo Internacional de Ciencias Sociales perteneciente a la Unesco. Hasta el momento ISA ha realizado 19 congresos y publica dos revistas: Current Sociology e International Sociology.
} 
individuos que, a lo largo de la historia del pensamiento social, han brindado explicaciones recurriendo no a la doctrina religiosa o a los mitos culturales sino a la observación y al análisis de las relaciones entre los hombres. En este sentido, nos atrevemos a proponer que los sociólogos existieron antes de la formalización de la sociología. Ejemplos hay varios: Abdel Rahman Ibn-Khaldun, Nicolás de Condorcet, Alexis de Toqueville, entre algunos de los más destacados. Por otro lado, fue necesaria la reinvención de una institución medieval que se convirtió en el símbolo del avance del saber moderno, rebasando el papel jugado por las academias reales o proyectos como la enciclopedia francesa. Las universidades modernas han sido los centros de producción del conocimiento y de los propios productores del conocimiento (Wallerstein, 1996), compromisos que derivaron en la aparición de muchas de las ciencias sociales clásicas —antropología, economía, historia, política y sociología-, así como de las recién constituidas. Del mismo modo, las universidades han sido las grandes organizadoras del conocimiento. Las instituciones universitarias, convertidas en centros de enseñanza, investigación y difusión - en concordancia con sus funciones sustantivas-, se transformaron convirtieron en el espacio donde se llevan a cabo acalorados debates por definir y redefinir los campos de acción de cada una de las ramas del conocimiento institucionalmente válido al interior de estos recintos, dando pie a la división y departamentalización del conocimiento.

Immanuel Wallerstein (2001) señala que, en el ámbito universitario, dividimos y enlazamos el saber de tres modos distintos: intelectualmente, como disciplinas; organizacionalmente como corporaciones; y culturalmente, como comunidades de estudios que comparten una serie de premisas elementales. De acuerdo al propio autor, una disciplina es una manera de reclamar un ámbito de estudio con su región particular, sus métodos apropiados y sus fronteras. Una disciplina define no solo algo sobre lo cual se piensa y cómo se piensa, sino también lo que está fuera de su alcance; decir lo que una disciplina es, es también decir lo que no 
es. Afirmar que la sociología es una disciplina es también afirmar que no es economía, historia o antropología, porque se considera que tiene un campo de estudio diferente, usa un conjunto de métodos distintos y tiene otro acercamiento al saber social (Wallerstein, 2001, p. 249).La sociología se abrió paso en el mundo académico demarcando su estatuto científico frente a formas de saber especulativo (Comte, 2006) y delimitando, por razón de su objeto de estudio y forma de investigación, un campo de conocimiento propio ante otras ciencias (Durkheim, 2007). Desde fines del siglo XIX, fueron inaugurándose cursos, cátedras, programas de licenciatura, publicaciones, posgrados, asociaciones y congresos en las universidades estadounidenses y europeas y, en menor medida, en instituciones latinoamericanas. Después de la Primera Guerra Mundial, la escuela de Chicago incorporó la etnografía como método de trabajo para el estudio de las ciudades a través de su enfoque de ecología social (Picó \& Serra, 2010) y, como consecuencia del papel jugado por las ciencias sociales en la Segunda Guerra Mundial, la investigación sociológica se valió del levantamiento de datos mediante el registro de cuestionarios (método de encuesta). El trabajo de Samuel Stouffer, The American Soldier (1950), dio el primer impulso para el desarrollo de la sociología estadística (Lizón, 2007), forma de investigación que floreció sobre todo en el Instituto de Investigación Social Aplicada de la Universidad de Columbia, bajo la dirección de Paul Lazarsfeld y Robert K. Merton (Linares Martínez, 2018). Durante la década de los 60 del siglo pasado, la revuelta estudiantil tuvo un claro referente en el pensamiento sociológico y figuras como Herbert Marcuse sirvieron de inspiración para los movimientos gestados en las universidades de los Estados Unidos, a pesar de los cuestionamientos que se hicieron por parte de los marxistas a la tradición sociológica como defensores del statu quo.

Pasado el fulgor de los años 60, comienza un proceso de reflujo de la sociología en términos teóricos y programáticos. La crisis de identidad impulsa a la disciplina sociológica a disgregarse en una multiplicidad de temáticas, y la división de trabajo 
entre teoría e investigación condujo a una desvinculación manifiesta: ni la teoría solicitaba de análisis empíricos para corroborar sus afirmaciones, ni la investigación social se valía de las aportaciones teóricas para guiar sus tareas. El final del consenso ortodoxo (Giddens, 1997) y el agotamiento de los diversos tipos de estructuralismos (Giddens, 2014) impusieron en la discusión sociológica de Europa un lenguaje sumamente elevado y ajeno a las situaciones experimentadas en los convulsos años de la crisis del estado benefactor, el ascenso del neoliberalismo y la caída del socialismo real. Alejada de las dificultades sociales urgentes, la teoría sociológica dejó de ser una fuente de consulta para comprender los problemas contemporáneos y su lugar en el debate intelectual se trasladó a otras modalidades de hacer sociología, como el ensayismo característico de la corriente posmoderna.Ha sido esta fragmentación del trabajo sociológico el que ha puesto en duda su papel como ciencia y como profesión. Los cuestionamientos contemporáneos a la sociología van desde su falta de cientificidad, pasando por la acusación de socavar los fundamentos morales del orden social y ser la excusa para la delincuencia, y llegar hasta el lenguaje innecesariamente complicado que utiliza para decir lo obvio. Así, la descalificación a la sociología es variada, tildándola como pseudo-ciencia, que intelectualmente no aporta nada, carente de un objeto de estudio definido, de ser simple sentido común envuelto en una jerga poco atractiva (Giddens, 2000, p. 14). Estos comentarios, además de ser una crítica malintencionada, ignoran funciones transcendentales que viene desempeñando la sociología desde sus orígenes hasta la época actual.

Raymond Boudon hace notar: "Es evidente que la sociología no ha logrado triunfos comparables a los de las otras ciencias más antiguas y con apoyos más sólidos" (Boudon, 2004, p. 216). El mismo autor apunta que la diversidad de la sociología puede ser captada a partir de cuatro tipos ideales: el de la sociología informativa o de "consultoría", dedicada a producir datos y análisis para la toma de decisiones; la sociología crítica, que identifica 
los defectos de la sociedad y propone remedios a los mismos; la sociología emotiva, que describe los fenómenos sociales de una manera vívida; y la sociología cognitiva, que tiene por objetivo la explicación de fenómenos sociales enigmáticos (Boudon, 2004, p. 215). Es importante destacar que los dardos dirigidos en contra de la sociología no son a un tipo en particular de los mencionados por Boudon. Los improperios no llevan dedicatoria y las afirmaciones se imputan a la totalidad de la disciplina. Como toda empresa humana, la sociología ha tenido a lo largo de su existencia éxitos y fracasos, y ha realizado buenos y malos trabajos. La visión reductiva que hay hacia ella magnifica sus errores e ignora sus aciertos.

\section{El itinerario latinoamericano de la sociología}

En América Latina, la labor de la sociología tuvo un camino diferente. Las diversas etapas por las que ha transitado el ejercicio de reflexión sociológica se han caracterizado por una constante: la incesante búsqueda de las causas que han llevado a la región latinoamericana a ser lo que es, lo que ha hecho a los practicantes de esta ciencia proclives a asumir un compromiso político. Las ciencias sociales en América Latina no disfrutan de los espacios de calma intelectual y relativo aislamiento frente a los problemas sociales como sí lo gozan las comunidades universitarias estadounidenses o europeas. Desde muy temprano, las ciencias sociales en nuestra región retomaron como un reto consustancial a su labor no solo conocer sino transformar las difíciles condiciones de vida de las mayorías. La urgencia por encontrar una salida a las condiciones de explotación, opresión, miseria y menosprecio, detectadas en un diagnóstico temprano por los pensadores sociales latinoamericanos, definió los enfoques teóricos y las perspectivas analíticas del trabajo sociológico en la región ${ }^{5}$.

Es ilustrativo de esta forma de concebir la función del sociológico en América Latina en títulos de antologías que el Consejo Latinoamericano de Ciencias 
A diferencia de las ciencias económico-administrativas, y una parte importante del campo de la psicología, la sociología no adoptó acríticamente los postulados elaborados en los centros académicos de las naciones industrializadas. En contraste, las áreas administrativas en las facultades latinoamericanas instituyeron su saber en textos traducidos de sus homólogos anglosajones y ampliamente difundidos en las universidades latinoamericanas. Bajo el supuesto de que los principios que gobiernan ese tipo de fenómenos se aplican de igual manera a los contextos latinoamericanos, los graduados de las denominadas escuelas de negocios dan por hecho que las condiciones de existencia social son similares en el norte industrializado y el sur latinoamericano, y reproducen doctrinas más que construir teorías. Por el contrario, los practicantes de las ciencias sociales, particularmente los sociólogos, se interrogaron desde un inicio sobre las grandes discrepancias que presenta la región latinoamericana frente a los Estados Unidos o Europa occidental. Es por eso que podemos afirmar que existe una sociología latinoamericana y no una ciencia gerencial o administrativa en igual sentido. El esfuerzo por encontrar la procedencia de esas disparidades llevó a pensar a los sociólogos latinoamericanos en términos regionales (todas las naciones del subcontinente compartían en mayor o menos medida los rasgos de lo que después se denominó atraso y subdesarrollo) y en periodos de largo alcance: las condiciones estructurales que limitan nuestro presente provienen del encadenamiento de procesos que se originaron desde las colonizaciones europeas.

En el ámbito intelectual, en el que se cultiva la sociología latinoamericana, también se han presentado casos en los que el propósito apunta a convertirnos en naciones ricas y prósperas, re-

Sociales (CLACSO) ha recopilado de autores consagrados dentro del ámbito de la región: Dominación y desigualdad: El dilema latinoamericano, de Florestan Fernandes (Fernandes, 2015); De la sociología del poder a la sociología de la explotación. Pensar América Latina en el siglo XXI , de Pablo González Casanova (González Casanova, 2015); La potencia plebeya. Acción colectiva e identidades indígenas, obreras y populares en Bolivia, de Álvaro García Linera (2015). 
plicando los mismos procedimientos que utilizaron las potencias mundiales para alcanzar su posición. Los seguidores de la doctrina del progreso, y otros adeptos a las ideas organicistas o evolucionistas, sembraron la idea de imitar el camino de las naciones industrializadas para romper con el tradicionalismo de las élites rurales y católicas. En México, por ejemplo, el grupo llamado de los "científicos", en el gobierno del dictador Porfirio Díaz, retomó el positivismo de Augusto Comte como bandera ideológica para llevar a cabo el proceso de acumulación salvaje que diera paso a la industrialización del país.

En términos propiamente sociológicos, la propuesta que buscó encontrar en la racionalidad instrumental la base sociológica para plantear un cambio social moderado, siguiendo las pautas occidentales del cambio cultural, recibió el nombre de teoría de la modernización y su principal exponente fue el sociólogo argentino Gino Germani (Kahl, 1986). Se manifestó, entonces, y existe todavía una significativa oposición por parte de las corrientes latinoamericanas por adoptar los métodos y técnicas de la investigación por encuesta tipo survey para validar las propuestas teóricas que fueron incorporándose al bagaje del pensamiento crítico latinoamericano. Este punto ha repercutido negativamente en el manejo de las técnicas cuantitativas en el ámbito latinoamericano, así como en el menoscabo que tiene para los profesionales de la sociología el no confirmar sus aseveraciones con extensos análisis cuantitativos. El uso de las estadísticas, cuando llega a hacerse de forma sistemática, es retomando de manera ligera, lo que informes oficiales o estudios desde la economía proponen. La desventaja para la sociología en el mercado de las representaciones profesionales es que, fuera del ámbito académico, el practicante de esta disciplina no es requerido por una demanda de instituciones y organizaciones públicas y/o privadas que no saben a ciencia cierta para qué sirve la sociología. Esta tendencia no es privativa de la sociología latinoamericana. En el espacio anglosajón también se dio una fuga para cimentar el trabajo sociológico en aquello que C. Wright Mills (2004) definió como el “em- 
pirismo abstracto". No ha sido hasta el siglo XXI cuando algunos investigadores han reivindicado el uso sistemático de las estadísticas y las bases de datos como forma de construir conocimiento fiable en el campo sociológico (Goldthorpe, 2018). La singularidad de la sociología de la región latinoamericana, en cuanto a la resistencia para ampliar el uso del procesamiento de datos como forma de comprobar hipótesis, radica en el carácter imperialista y encubridor que le fue atribuido al método cuantitativo por parte de quienes definían el perfil del sociólogo latinoamericano.

En el contexto latinoamericano, la institucionalización de la sociología y de las ciencias sociales, en general, corrió a la par del ascenso del nacionalismo industrializador. A decir de un observador estadounidense "los países más grandes por primera vez intentaron lograr un rápido desarrollo económico mediante la política de industrialización y recurrieron a las ciencias sociales, particularmente a la economía, en busca de directrices" (Kahl, 1986, p. 16). En este sentido, las ciencias sociales en América Latina adoptaron primordialmente un enfoque centrado en el cambio sociocultural y socioeconómico donde la presencia del Estado era imprescindible para alcanzar las metas históricas planteadas después de la posguerra.

De esa forma, las ciencias sociales mantuvieron una relación ambivalente frente al poder político. Por un lado, los expertos en ciencias sociales consideraron la acción del Estado como la principal palanca para el desarrollo y, por lo mismo, apoyaron habitualmente los proyectos económicos incubados en las agencias gubernamentales. En este tipo de participación tuvo un papel central la Comisión Económica para América Latina (CEPAL), dirigida por Raúl Prebich. Y por otro lado, un número considerable de sociólogos observaban con recelo el papel que cumplía el Estado en el proceso de transformación social y advertían en las políticas estatales un proyecto para consolidar un proyecto de industrialización capitalista. El apoyo popular que recibieron algunos gobiernos por llevar a cabo significativas transformaciones, como el reparto agrario o una legislación 
favorable a los trabajadores, era percibido por los especialistas en ciencias sociales como la apuesta por un proyecto ajeno a los intereses de las clases trabajadoras debido a que los gobiernos nacionalistas habían pactado con sus respectivas burguesías respetar las reglas básicas del orden económico capitalista. La única posibilidad que veían los científicos sociales era que las organizaciones autónomas de campesinos y trabajadores urbanos, en una gran alianza popular, empujaran a los gobiernos a enfrentar a las grandes empresas nacionales y trasnacionales, así como forzar a los medianos y pequeños propietarios a subirse al tren de la revolución social. En América Latina, las facultades e institutos de ciencias sociales se desenvolvieron en un ambiente dividido entre el apoyo al papel del Estado como referente del desarrollo y la crítica a los poderes económico y político, mostrando las limitaciones estructurales para poder consolidar un desarrollo que fuera autónomo del control del sistema financiero internacional y de las grandes corporaciones trasnacionales.

Las ideas liberales que inspiraron las constituciones de las naciones latinoamericanas pronto fueron dejadas atrás por los pensadores sociales de la región. La pronta recepción de las ideas socialistas y anarquistas en América Latina respondían a tres mecanismos estructurales de ese periodo histórico: el fracaso de las formas políticas representativas, el impulso exógeno de la industrialización y, con ello, la incorporación de formas de organización laboral, ya maduras, provenientes de Europa.

En el primer caso, desde el nacimiento de las jóvenes repúblicas existió una discrepancia casi absoluta entre lo estipulado en los códigos constitucionales que consagran la elección de los gobiernos por la vía electoral y la proliferación de dictaduras militares. Estas se convirtieron en la manera habitual de ejercer el poder en prácticamente la totalidad de estos países. Los caudillos militares sirvieron, ante todo, a los poderes tradicionales: la Iglesia y los terratenientes, así como a las potencias imperialistas: Gran Bretaña y Estados Unidos, cuyos representantes inclusive 
elegían a estos mandatarios de forma directa, como sucedió en México en 1913, cuando el embajador de Estados Unidos Henry Lane Wilson confabuló contra el presidente electo democráticamente Francisco I. Madero para derrocarlo por medio de un golpe de Estado. En el segundo caso, la división internacional del trabajo imperante a finales del siglo XIX no impidió que en esa época comenzaran los primeros centros fabriles financiados por capitales foráneos a la región. La expansión del capitalismo permitió la instalación del ferrocarril y los sistemas bancarios dominados por capitales británicos y estadounidenses, principalmente. Las primeras industrias se caracterizaron por una sobreexplotación de los trabajadores, quienes pronto intentaron organizarse para conseguir un mínimo de derechos laborales. Luego, las ideas de que en Europa habían dado pauta a la organización obrera se trasladaron al otro lado del Atlántico, inspirando a intelectuales latinoamericanos, quienes se convirtieron en pioneros de la crítica social al naciente orden capitalista industrial. Las jornadas por la reivindicación del trabajo se convirtieron en la forma por antonomasia de la lucha social.

De entre las tendencias socialistas, el marxismo ha sido la corriente que mayor influencia ha tenido en América Latina. Las ideas inspiradas en Marx impregnaron tanto a las organizaciones de masas como a intelectuales pioneros en hacer ciencia social (Löwy, 2007). Dentro de esta perspectiva, sobresale el trabajo de José Carlos Mariátegui (2007), Siete ensayos de interpretación de la realidad peruana, obra que sigue siendo un referente para los estudios sociológicos de América Latina, ya que introduce tópicos referentes al indio, la tierra, la instrucción universitaria, la religión y el regionalismo, todas ellas temáticas no consideradas de manera suficiente por la teoría marxista.

El marxismo, que durante la década de los 30 en el siglo $X X$ no tuvo una recepción inmediata en las aulas universitarias, ingresaría a las mismas tres décadas más tarde por conducto de una serie de jóvenes investigadores que vieron en la revolución cubana la respuesta a la insuficiente capacidad teórica y prác- 
tica para resolver las condiciones de atraso y subdesarrollo heredados de los regímenes conservadores, así como la falta de alternativas al estancamiento económico y la falta de viabilidad distributiva del periodo de industrialización por sustitución de importaciones. La teoría de la dependencia inspirada en una visión neo marxista, consideró, por primera vez, el pasado colonial y las condiciones del sistema capitalista mundial como las causas principales que mantenían las condiciones de sobrexplotación y atraso económico. La solución era romper esos lazos de dependencia y buscar una vía alternativa al modelo de desarrollo hasta entonces imperante. Para los seguidores de esa corriente, la trasformación radical era la única posibilidad de solucionar de raíz los problemas de Latinoamérica.

Los cambios económicos y políticos ocurridos en América Latina en la década de los 70 del siglo pasado irían en sentido contrario a las predicciones esbozadas por los dependentistas. La crisis de la deuda y el paso de la dictadura a la democracia echarían abajo cualquier posibilidad de replicar los ensayos revolucionarios tipo Cuba o Nicaragua. El agotamiento de la visión dependentista se dio en el contexto de la "década perdida", la crisis fiscal de Estado, la caída del socialismo real y la adopción en América Latina de un nuevo patrón de acumulación menos dependiente de la intervención estatal, con una economía más abierta a las inversiones extranjeras y al comercio internacional. El trabajo sociológico se limitó a realizar una crítica al neoliberalismo por los estragos que las medidas de política económica, que adoptaron los gobiernos latinoamericanos — siguiendo las directrices del Fondo Monetario Internacional-, tuvieron en el nivel de vida de las clases trabajadoras.

Distinta fue la reacción de los sociólogos de la región latinoamericana ante los cambios políticos que se presentaron. Con el colapso de la Unión Soviética se destensaron las relaciones ideológicas que confundían la lucha por la democracia con cambios radicales en el orden económico y social. La transición de gobiernos dictatoriales a gobiernos electos democráticamente constru- 
yó un nuevo escenario donde la perspectiva sociológica se vio disminuida frente al discurso proveniente de la ciencia política y los derechos humanos.

No aparecieron nuevas propuestas dentro del ámbito académico y el trabajo de los sociólogos se dispersó en una pluralidad de problemáticas sin tener un eje teórico articulador. Habría que esperar hasta el cambio de siglo para ver una renovación del pensamiento crítico latinoamericano. Aunque gestado en la última década del siglo XX, fue con el inicio de la nueva centuria cuando irrumpió esta nueva propuesta que condensa una serie de reivindicaciones no contempladas desde las posiciones marxistas y dependentistas: la resistencia de los pueblos originarios, el feminismo, los derechos de la diversidad sexual, la defensa de la naturaleza, todo aquello que Boaventura de Sousa (2009)nombró como "la sociología de las ausencias". La sociología fue desbordada por este nuevo enfoque que rápidamente se extendió en los centros universitarios latinoamericanos. Las disciplinas sociales tradicionales, como la sociología, comparten ahora con la teoría literaria, los estudios de género, los estudios decoloniales y otras especialidades el discurso crítico que se produce desde el espacio académico ${ }^{6}$. Cuando Jair Bolsonaro dirige sus ataques a la sociología y la filosofía en realidad está enfocando sus agresiones a esta pléyade de investigaciones multidisciplinarias.

6 La Asociación Latinoamericana de Sociología (ALAS), fundada durante el Primer Congreso Internacional de Sociología en 1950 es una muestra de ello. Un análisis de la forma cómo está organizada la ISA en 57 comités de investigación que incluyen rubros directamente vinculados con las especialidades sociológicas: sociología de la vejez, sociología del ocio, historia de la sociología, sociología del derecho, etcétera, o bien con objetos construidos desde una perspectiva sociológica: investigación comunitaria, investigación sobre el futuro, políticas sociales, entre otros, contrasta con la manera en que se organiza ALAS en grupos de trabajo. Para el congreso de Perú en 2019 se conformaron 25 grupos de trabajo que incluyen, además de ciertas propuestas ya tradicionales en estas reuniones referentes a cuestiones de ciencia y tecnología, aspectos rurales o urbanos, estudios demográficos, etc. y otros como: alimentación y cocinas en las Américas, géneros y feminismos, imaginarios y memorias críticas decoloniales, grupos que dan cuenta de la heterogeneidad que se está moviendo en el ambiente académico latinoamericano. 
Las epistemologías del sur contaron como referente los movimientos antiglobalización reunidos en el Foro Social Mundial y, con cierto distanciamiento, a los llamados gobiernos progresistas o posneoliberales que se instalaron en Venezuela, Ecuador, Brasil, Bolivia, Argentina, Uruguay y Chile en el primer decenio del siglo XXI. Por lo mismo, fue, dentro de un marco de desilusión por las promesas incumplidas de la globalización neoliberal y la democracia restringida, pero también en un periodo de prosperidad económica sostenido en el precio internacional de las materias primas, cuando las propuestas decoloniales destacaron a partir de los trabajos de un considerable número de figuras relevantes. En ese sentido, la opción decolonial fue una propuesta optimista inspirada por triunfos en el terreno, político, legislativo, ideológico, mediático y hasta editorial. A finales de la segunda década del siglo XXI, el panorama regional no es tan positivo. Las derrotas de los gobiernos de izquierda, el avasallamiento contra el gobierno de Venezuela, el encarcelamiento de Luis Ignacio Lula da Silva, la persecución a Rafael Correa, el triunfo de la derecha argentina con Mauricio Macri, el giro político conservador en Chile marcan el fin del ciclo progresista. Los movimientos sociales que generaron un apoyo global como el que suscitó el Ejército Zapatista en Chiapas en la última década del siglo XX han perdido presencia $\mathrm{y}$ hay un reflujo de los movimientos sociales.

El horizonte para la sociología pinta poco alentador y el espacio académico parece no poder expandirse indefinidamente sin gobiernos sensibles dispuestos a realizar las aportaciones financieras suficientes a las universidades. Para la sociología, tal como se ha venido practicando en América Latina, se presenta una disyuntiva: profundizar en el, hasta el momento, paradigma dominante de la decolonialidad que tiene como principal objetivo descolonizar a las ciencias sociales, o bien recuperar los espacios institucionales y practicar una sociología informativa o "de consultoría" (Boudon, 2004).

Para la primera alternativa, existe un mercado académico que puede nutrirse a sí mismo a través de programas de pregrado, cur- 
sos, posgrados, publicaciones. El riesgo de esta elección es carecer de un vínculo directo con los movimientos de masas, como sucedió con el marxismo; también está el problema de construir los espacios laborales para las nuevas generaciones de egresados de estos programas. La segunda opción resulta poco atractiva para los jóvenes idealistas que eligen estudiar sociología con el propósito de transformar al mundo: una sociología más profesionalizante ampliaría el mercado de trabajo del egresado, cambiando la imagen de intelectual radicalizado, como la que utilizó Bolsonaro, a una perfil más cercano al del psicólogo o el economista, quienes ofrecen sus servicios especializados sin renunciar a sus convicciones o principios.

\section{Conclusiones}

Si la sociología es un deporte de combate, tal como lo manifestó Pierre Bourdieu (2018) hace unos años, le toca a los sociólogos subir al ring de tiempo en tiempo para defender el derecho de esta disciplina académica a considerarse una ciencia y a recibir el reconocimiento y los recursos necesarios para poder desarrollarse. El giro de la política en Brasil ha puesto en entredicho nuevamente a la sociología y a pintarla como una carrera universitaria sin beneficio social ni futuro profesional. Viniendo los comentarios de quien los dice, podría parecer un juicio sin importancia, pero las posibles repercusiones son bastante severas para los sociólogos brasileños. Este hecho es propicio para renovar el espíritu de quienes nos han legado obras cuya temática principal es la defensa de la sociología, así como de quienes de igual forma han respondido a la pregunta ¿para qué sirve la sociología? Para ello, fue necesario analizar la manera en que la sociología fue cambiando para responder a los desafíos que fueron presentándose con el tiempo. De manera particular, una defensa de la sociología significa reflexionar sobre el camino que ha transitado esta ciencia social en América Latina y los roles que ha jugado ante su gran interlocutor, que es el Estado, las teorías de las que se ha valido para interactuar en los espacios universitarios y los espacios públicos. Finalmente, en un futuro, la 
trascendencia de la sociología se reconocerá por el tipo de investigaciones que llegue a realizar.

\section{Referencias}

Anderson, P. (1979). Consideraciones sobre el marxismo occidental . México D. F.: Siglo XXI.

Armenakas, S. S. (6 de mayo de 2019). More than 800 institutions sign Harvard letter calling on Brazil to fund philosophy, sociology. The Harvard Crimson. Disponible en: https://www. thecrimson.com/article/2019/5/6/sociology-open-letter/

Birnbaum, N. (1982). ¿El final de la sociología? En T. Bottomore (Ed.), La miseria de la sociología (pp. 105-127). Madrid: Tecnos.

Boudon, R. (2004). La sociología que realmente importa. Papers. Revista de Sociología, 215-226.

Bourdieu, P. (2008). Cuestiones de sociología. Madrid: Akal.

Bourdieu, P. (3 de enero de 2018). Pierre Bourdieu. La Sociología es un deporte de Combate. Disponible en: https://www.youtube. com/watch?v=YUZW1wPxK_A

Bourdieu, P., Chamboderon, J. C. \& Passeron, J. C. (1981). El oficio del sociólogo. México: Siglo XXI.

Consejo Latinoamericano de Ciencias Sociales. (15 de mayo de 2019). 15M, Greve Geral da Educação no Brasil. Disponible en: https:/ / www.clacso.org/15m-greve-geral-da-educacao-no-brasil/

Comte, A. (2006). Filosofía positiva. México D.F.: Porrúa.

de Sousa Santos, B. (2009). Una epistemología del sur. México D.F.: Siglo XXI.

Durkheim, E. (2007). Las reglas del método sociológico. México D.F.: Ediciones Coyoacán.

Fernandes, F. (2015). Dominación y desigualdad: El dilema social latinoamericano. Buenos Aires: CLACSO, Siglo XXI.

Ferrarotti. F. (1982). Comentarios introductorios sobre el tema: ¿Está en crisis la sociología? En T. Bottomore (Ed.), La miseria de la sociología (pp. 15-22). Madrid: Tecnos.

Galarraga, N. (14 de abril de 2019a). Olavo de Carvalho, el antimarxista que susurra al oído del clan Bosonaro. El País. Disponible en: https:/ /elpais.com/internacional/2019/04/14/actualidad/1555194270_543597.html 
Galarraga, N. (13 de mayo de 2019b). Bolsonaro ataca la universidad pública, la ciencia y el pensamiento crítico. El País. Disponible en: https:/ / elpais.com/sociedad/2019/05/11/actualidad/1557603454_146732.html

García Linera, Á. (2015). La potencia plebeya. Buenos Aires: CLACSO, Siglo XXI.

Giddens, A. (1997). Las nuevas reglas del método sociológico. Crítica positiva de las sociologías comprensivas. Buenos Aires: Amorrortu.

Giddens, A. (2000). En defensa de la sociología. Madrid: Alianza.

Giddens, A. (2014). Problemas centrales en teoría social. Buenos Aires: Prometeo.

Global Voices. (19 de mayo de 2019). Brasileños toman las calles en todo el país para protestar contra los recortres de Bolsonaro a la educación pública. Disponible en: https:/ /es.globalvoices.org/2019/05/19/ brasilenos-toman-las-calles-en-todo-el-pais-para-protestarcontra-recortes-de-bolsonaro-a-la-educacion-publica /

Goldthorpe, J. (2018). La sociología como ciencia de la población. Madrid: Alianza.

González Casanova, P. (2015). De la sociología del poder a la sociología de la explotación. Buenos Aires: CLACSO, Siglo XXI.

Gouldner, A. (2000). La crisis de la sociología occidental. Buenos Aires: Amorrortu.

Habermas, J. (1999). Problemas de legitimación en el capitalismo tardío. Madrid: Cátedra.

Habermas, J. (2011). Escritos filosóficos. Fundamentos de la sociología según la teoría del lenguaje. Madrid: Paidós.

Jacá, B., \& Galarraga, N. (16 de mayo de 2019). Miles de estudiantes marchan contra los recortes de Bolsonaro. El País.

Kahl, J. (1986). Tres sociólogos latinoamericanos. Germani, González Casanova, Cardoso. México D.F.: UNAM .

Kon, I. (1982). La crisis de la sociología occidental y el segundo descubrimiento del marxismo. En T. Bottomore (Ed.), La miseria de la sociología (pp. 35-44). Madrid: Tecnos.

Lahire, B. (2006). El espíritu sociológico. Buenos Aires: Manantial.

Lahire, B. (2016). En defensa de la sociología: Contra el mito de que los sociólogos son unos charlatanes, justifican a los delincuentes y distorsionan la realidad. Buenos Aires: Siglo XXI. 
Linares Martínez, F. (2018). Sociología y teoría social analíticas. La ciencia de las consecuencias inintencionadas de la acción. Madrid: Alianza.

Lizón, Á. (2007). La otra sociología. Madrid: Montesinos.

Löwy, M. (2007). El marxismo en América Latina. Santiago de Chile: LOM.

Mariátegui, J. C. (2007). 7 Ensayos de interpretación de la realidad peruana. Caracas: Biblioteca Ayacucho .

Noticias de América Latina. (26 de abril de 2019). Brasil: Bolsonario plantea desfinanciar las facultades de filosofía y sociología. Nodal: Noticias de América Latina. Disponible en https:// www.nodal.am/2019/04/brasil-bolsonaro-plantea-desfinanciar-las-facultades-de-filosofia-y-sociologia /

Ogien, A. (2008). Las formas del pensamiento. La sociología después de Wittgenstein. Buenos Aires: Nueva Visión.

Passeron, J. C. (2011). El razonamiento sociológico. El espacio comparativo de las pruebas históricas. Madrid: Siglo XXI.

Picó, J. (2003). Los años dorados de la sociología (1945-1975). Madrid: Alianza.

Picó, J. \& Serra, I. (2010). La escuela de Chicago de sociología. Madrid: Siglo XXI.

Portes, A. (2004). La sociología en el continente: Convergencias pretéritas y una nueva agenda de alcance medio. Revista Mexicana de Sociología, 66(3), 447-483.

Requena Santos, F. (2014). Teoría sociológica aplicada. Barcelona: Anthropos.

Touraine, A. (1978). Introducción a la sociología. Barcelona: Ariel.

Trindade, H. (2007). Las ciencias sociales en América Latina en perspectiva comparada. México: Siglo XXI.

Velázquez, M. Á. (4 de agosto de 2019). Si AMLO fracasa, AL quedará en la oscuridad: De Sousa. La Jornada. Disponible en: https:/ / www.jornada.com.mx/ultimas/politica/2019/08/04/siamlo-fracasa-al-quedara-en-la-oscuridad-de-sousa-3876.html

Wallerstein, E. (1996). Abrir las ciencias sociales. México: Siglo XXI.

Wallerstein, I. (2001). Conocer el mundo, saber el mundo: El fin de lo aprendido una ciencia social para el siglo XXI. México: Siglo XXI.

Wright Mills, C. (2004). La imaginación sociológica. México: Fondo de Cultura Económica. 